\title{
PRELIMINARY STUDY ON THE PREVENTIVE PROTECTION OF ROCKERY IN THE MOUNTAIN RESORT BASED ON THE COMPREHENSIVE DIGITAL TECHNOLOGY
}

\author{
Wu Xiangyan ${ }^{1 *}$, Xie Lindong ${ }^{2}$,Chen Dong $^{3}$,Wang Yiru ${ }^{1}$,Wang Xiaolu ${ }^{1}$, Ma Fengle ${ }^{1}$, \\ ${ }^{1}$ School of architecture, Central Academy of Fine Arts, 8 Huajiadi South Street,Beijing,China \\ ${ }^{2}$ Beijing Qingda Heyi Technology Co., Ltd \\ ${ }^{3}$ Chengde Cultural Relics Bureau
}

KEY WORDS: Preventive Protection, Mountain Resort, Rockery, Integrated Digital Technology, Assessment.

\begin{abstract}
:
The concept of preventive protection originates from the European heritage protection field. Nowadays, a complete knowledge system and normative reference framework have been formed in the field of museum collection cultural relics. However, it is just beginning in the field of traditional garden heritage protection. Based on the review of the theories and practices of the preventive protection of international historical building and traditional garden heritage, this paper makes a comprehensive survey, photo and modeling record of the rockery of Mountain Resort with the help of the current comprehensive digital mapping technology. Based on this, the paper combines the historical data files to carry out the comprehensive analysis and evaluation of the authenticity, destruction and safety of the present rockery; moreover, taking Jinshan as an example, the main points of digital surveying and mapping of large-scale rockery are summarized; Finally, summarize the current problems of rockery and put forward preventive protection suggestions. It is hoped that through this study, the case of preventive protection of Royal Garden heritage in Qing Dynasty will be enriched, and a new idea will be provided for the protection of Royal Garden heritage in Qing Dynasty.
\end{abstract}

\section{INTRODUCTION}

Chengde Mountain Resort ${ }^{1}$ is a large landscape garden built during the Kangxi and Qianlong period of the Qing Dynasty. Based on the natural landscape, it organically combines rockery-piling, water-planning and architecture construction, forming a unique model of garden integrating the beauty of Jiangnan literati garden with the grandeur of the royal garden in the north. It is difficult to distinguish rockery and natural mountain in the garden; Meandering hill and lake sets each other off beautifully, forming the landscape skeleton; The rockery is integrated with architecture, plants, water and other elements, either as the main scenery or secondary feature of the garden, showing unique ingenuity. There are nearly 100 rockeries in the Mountain Resort, with staircase mountain in Yunshan Shengdi and rocky path of Wanhe Songfeng of palace area;Yanyulou, Jinshan, Wenyuan shizilin and other large and medium-sized rockeries of lake area; Shanjinxuan rockery of mountain area and so on. The existing rockeries in the Mountain Resort is an important model for studying the art of rockery in the northern imperial garden. However, the research on rockery is basically zero. The rockery in the garden has experienced natural wind, frost, rain and snow, war, and human destruction in the process of 300 years of historical evolution, presenting the danger of rock capsizing, rock falling off, loosening, weathering and so on. Therefore, it is very urgent to carry out preventive protection research on the rockery.

This article focus on the protection and restoration of the Mountain Resort's rockery, using modern digital technologies such as $3 \mathrm{D}$ laser scanning, close-range photogrammetry and aerial photography to collect data on the unique rockery to complete an accurate 3D spatial digital model. Afterwards, put it into the virtual reality space to reproduce the scene. The digital archives of the Mountain Resort is finally established to realize a variety of man-machine interactive and innovate the protection and display of heritage. At the same time, through the digital measurement of the existing rockery, combining with

\footnotetext{
${ }^{1}$ It is the biggest royal garden in the world, as well as World Cultural Heritage. It is also called "Chengde Mountain Summer Resort"
}

interviews in order to summarize the basic rockery techniques of the Mountain Resort; Evaluate and classify the existing rockeries, and puts forward scientific protection strategies to preserve and inherit this important garden heritage.

\section{INTERNATIONAL AND DOMESTIC DEVELOPMENT OF PREVENTIVE PROTECTION THEORIES}

\subsection{Concept of preventive protection}

Preventive protection is an extremely important issue in the field of cultural relics protection in recent years. In 1931, the League of Nations Museum Bureau (predecessor of International Council of Museums) sponsored the first academic conference on the application of scientific and technological methods to the inspection and preservation of artworks, and put forward the concept of preventive protection for the first time, which mainly refers to the control of the preservation environment of cultural relics, especially the control of the temperature and humidity of the preservation and display environment of cultural relics(Elena Lucchi.et al.2018a). Later, with the development of science and technology and heritage protection concepts, preventive protection theory gradually expanded from the field of museums to the fields of architectural heritage and historical gardens, and formed an independent discipline system covering various elements such as technology, planning, policy, and law(Wu Meiping,2011a).In 2008, the International Centre for the Study of the Preservation and Restoration of Cultural Property (ICCROM) pointed out that the preventive protection is to take all measures and actions to prevent or reduce the possible future deterioration and damage of the heritage. This process needs to be based on the understanding of the deterioration mechanism, the establishment of a monitoring system, regular maintenance and records, and full public participation. It is possible to eliminate all the causes of deterioration of the heritage in the initial stage, which is not only a technical problem, but also an economic and social problem(Li Aiqun, et al.2021 a). 


\subsection{Research on preventive protection of architectural heritage}

The protection of architectural heritage aims to protect the authenticity and integrity of the value carried by the heritage. In the concept of architectural heritage protection, preventive protection adopts scientific and technological means to analyze its existing safety hazards, and eliminate or reduce them in a targeted manner, which can ensure the true and complete preservation and inheritance of the architectural heritage value to the greatest extent(Wu Meiping,2011a). The preventive protection of architectural heritage at the end of the 20th century and the beginning of the 21 st century was discussed as a special topic by academic circles. The preventive protection of architectural heritage was divides into three levels:"primary prevention_-prevention of the inducements of adverse effects (health degradation); secondary prevention_early detection of symptoms caused by adverse effects through monitoring methods; tertiary prevention-taking measures to prevent Avoid the spread of adverse effects or produce new side effects".(Wu Meiping,2020).On the basis of Wu Meiping's research, Li Aiqun and others further improved the preventive protection framework of architectural heritage, and divided the preventive protection of architectural heritage into four stages: basic information collection, risk factor identification, risk identification and risk prevention as shown in Figure 1(Li Aiqun et al.2021a)..Since the 21 st century, with the rapid development of digital technology, HBIM has provided a number of characteristics that are superior to traditional methods and has emerged: HBIM offers several advantages compared to traditional methods, such as: 1) centralization of information; 2) analysis of the different interventions carried out and; 3) fluid communication between agents. This set of advantages makes possible the use of HBIM approaches for structural analysis, damage assessment, restoration, documentation and digital representation (Rm, A.et al. 2021a).

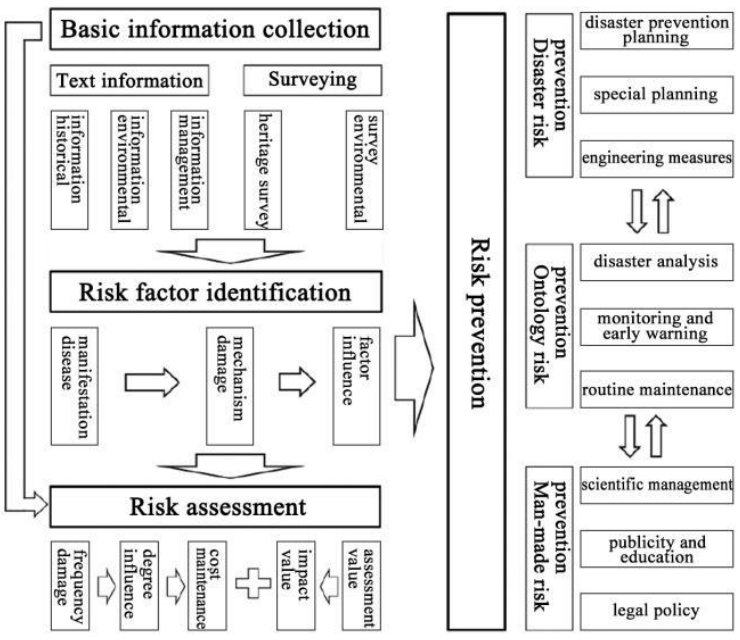

Figure 1. Preventive protection framework system (Li Aiqun, et al. 2021a)

\subsection{Research on preventive protection of Chinese historical gardens}

In China, Research on preventive protection of historical gardens lags behind those related to architectural heritage. It has just started in the past ten years, with few research results and no systematic theoretical research framework. Through the analysis and research of the relevant documents retrieved from the CNKI database, it is found that: The research objects are mainly private gardens, and the research content involves "digital information collection", "preventive conservation", "monitoring and early warning" and other aspects. Among them, the research results of combining the current emerging digital surveying and mapping technology to collect and record traditional garden spatial information, build heritage information databases or build information platforms are relatively rich, while the results directly focusing on "preventive protection" and "monitoring and early warning" are scarce. CNKI has retrieved five typical literatures, four of them are about preventive protection of private gardens: "Research on the Pre-conservation of Spatial Characteristics of Humble Administrator's Garden"( Wang Qingqing et al, 2020a), the paper analyzes the spatial characteristics of Humble Administrator's Garden and highlights the preventive protection of spatial structure;"Study on Pre-protection of Plant Landscape Space in Lingering Garden" (Wang Zhe et al., 2020a) analyzes the characteristics and existing problems of the garden plant space and puts forward the corresponding preventive protection countermeasures;"Study on the Pre-conservation of the Masterof-Nets Garden and its Surrounding Alleys" (Mo Jichan et al., 2020a) focuses on the overall protection of the surrounding environment of the Master-of Nets Garden;"Research on Preconservation of Tuisi Garden from the Perspective of Tourism Development" (Chen Xin et al., 2020) puts forward preventive protection strategies, such as standardizing preventive protection mechanism, strengthening the research and control of tourist capacity, limiting the height of the surrounding environment of Tuisi Park, and enhancing the scientific nature of heritage monitoring by using 3D digital mapping. Mei Wen's Master's thesis (2019)"Research on Monitoring and Early Warning System of Garden Heritage"taking Suzhou classical gardens as an example, the index system of landscape heritage monitoring and the grading evaluation model of landscape heritage monitoring and early warning were constructed. The above research results are all beneficial attempts in the direction of preventive conservation of garden heritage and provide some references for this study.

\section{RESEARCH ON HISTORICAL GARDENS UNDER THE BACKGROUND OF COMPREHENSIVE DIGITAL TECHNOLOGY}

Since the 21st century, digital technology has continuously expanded in the field of international and domestic heritage research and practice, gradually improved the methods of heritage information recording, storage, analysis, and dissemination, making heritage protection more scientific and efficient. The CIPA International Symposium has been held for 4 consecutive sessions with the theme of digital heritage records and positioned it as a key area for future development(Guo xiaotong et al., 2020a).

\subsection{Digital research on rockery of the historical gardens}

In the past ten years, Chinese scholars have broken through the limitations of traditional research methods and methods in the research of historical gardens and rockery, and have gradually entered a new era of digitalization. Bai Xuefeng first tried to use 3D laser scanning to express a single stone, and compared with traditional painting expression, at the same time building a rockery database, exploring the digital method of rockery(Bai Xuefeng,2015); In order to map out the complex structure and shape of rockery as accurately as possible, Gu Liyuan and others used photogrammetry as a means to collect and model the rockery of Xumi Lingjing in the Summer Palace by using $\mathrm{UAV}$ and 3D digital technology, summarized its advantages and 
feasibility, pointed out the problem of lack of local data $(\mathrm{L} . \mathrm{Gu}$ et al,2016a ); In private gardens, Yu Mengzhe and Lin Xi used close-range photogrammetry and 3D laser scanning to study and discuss the shape, material, color and data accuracy of the rockery and pond in Huanxiu garden and Couples retreat Garden(M. Yu et al, 2017a ). The study of Qianlong Garden in the Forbidden City under the background of digitization uses 3D laser scanning as the main measurement method. After laser scanning of the rockery in the garden, the collected $3 \mathrm{D}$ point cloud data is used for 3D modeling, and then restored and labeled of the pavement and texture through photogrammetry in the later period (Wang Shiwei et al, 2018); Zhang Qingping and others used ground laser scanning and UAV photogrammetry technology to carry out 3D digital mapping of Sui Garden in Suzhou(Q. Zhang et al, 2018a ); Liang Huilin and others applied multiple technologies and angles method of 3D comprehensive surveying and mapping of classical gardens to obtain a complete 3D model of Suzhou Huanxiu Garden(H. Liang et al, 2018a ); Yang Chen and others conducted a study on the spatial characteristics and heritage of rockery in Yuyuan Garden in Shanghai based on 3D point cloud technologies (Yang Chen et al, 2017a ).

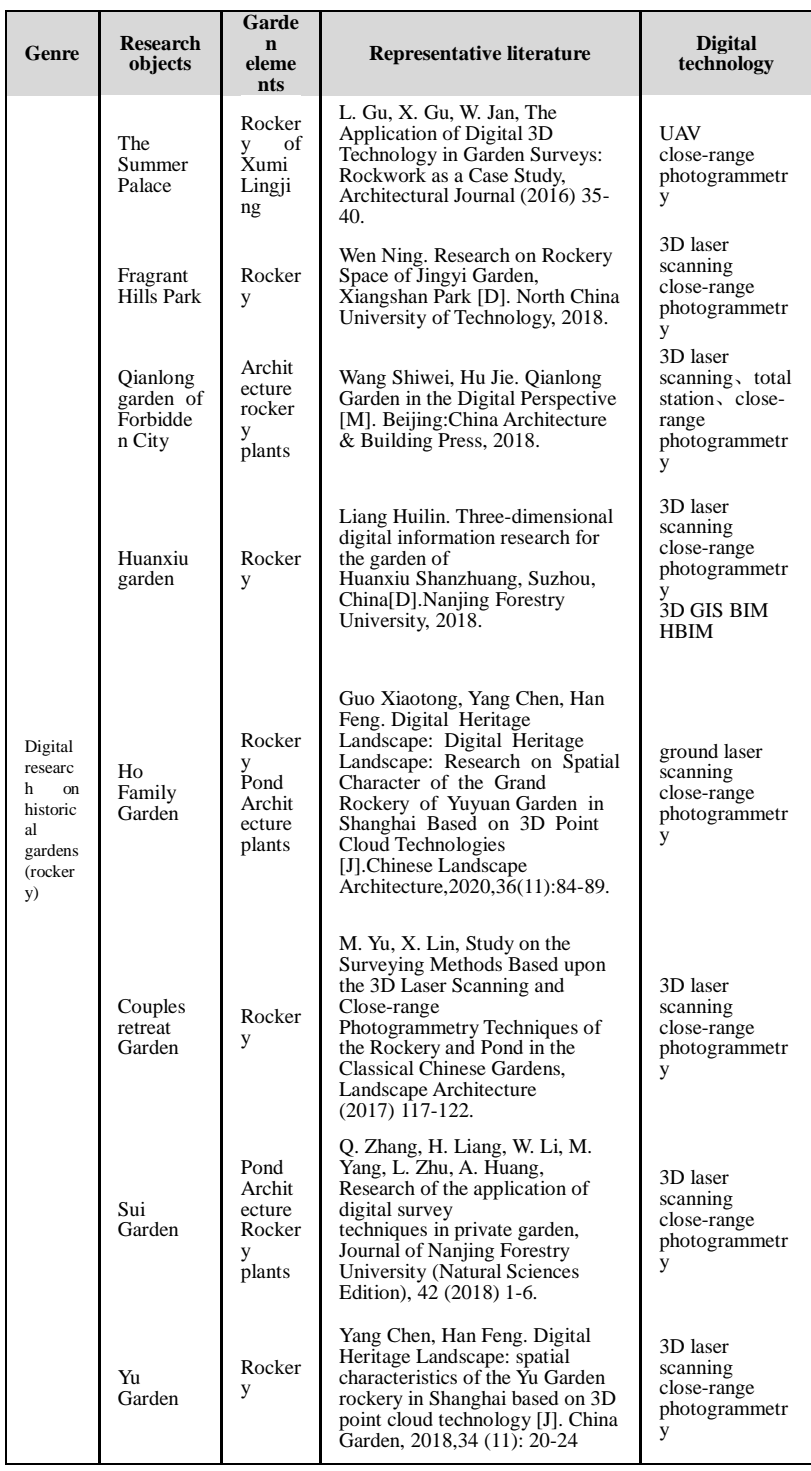

Table 1. Summary of the key literature of domestic historical garden digitization research in recent years.

\subsection{Integrated digital surveying and mapping technology}

The collection and recording of historical garden heritage information is always the basic premise and guarantee for heritage research. Under the background of rapid update and iteration of digital information technology, the comprehensive use of multiple surveying and mapping technologies for heritage information collection has become a new trend in the development of the industry. Surveying and mapping methods such as total station, 3D laser scanning, close-range photogrammetry, and oblique photogrammetry have their own advantages and limitations, as shown in Table 2. The integration of two or more mapping methods can overcome the limitations of single digital mapping technology and improve the effect and efficiency of cultural heritage mapping(Liang Huilin,2018). Related domestic and foreign studies have shown that the combination of close-range photogrammetry and 3D laser scanning is the best choice for the acquisition, recording, management and analysis of historical garden cultural heritage data including rockery, pools and other complex shapes. The process of multi-technology comprehensive surveying and mapping of historical gardens is shown in Figure 2.

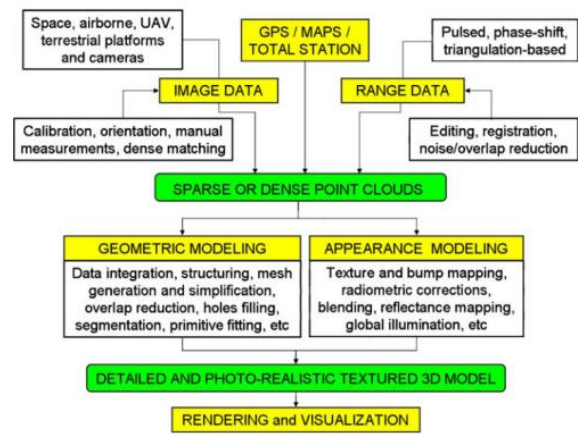

Figure 2. The multi-sensor and multi-resolution 3D modeling pipeline based on the integration of different techniques for the generation of point clouds and textured 3D models(REMONDINO F,RIZZIA A, 2010a)

Most of the data obtained through the above-mentioned equipment and technologies are point cloud data. Therefore, it is necessary to master the point cloud-based data fusion technology, and match and splice data from different sources in the same or similar format. Through data fusion, point clouds or models can be completely matched. In the process of digitization of historical gardens, different objects need to adopt different digitization technologies. Therefore, they are faced with the integration, editing and display of big data after digitization. Through the combination, correlation and combination of data and information from multi-sensor information sources, more precise location and data accuracy can be obtained, thus realizing the matching of digital scene and dynamic information to present the real-time and complete evaluation. The above process is data fusion.

\begin{tabular}{|c|c|c|c|c|}
\hline $\begin{array}{l}\text { Equip } \\
\text { ment t } \\
\text { ype }\end{array}$ & $\begin{array}{l}\text { Working principl } \\
\text { e and characteris } \\
\text { tics }\end{array}$ & Advantage & Disadvantage & $\begin{array}{c}\text { Scope of } \\
\text { application }\end{array}$ \\
\hline $\begin{array}{l}\text { Tot al } \\
\text { station }\end{array}$ & $\begin{array}{l}\text { The total station el } \\
\text { ectronic distance } \\
\text { meter integrates th } \\
\text { e functions of hori } \\
\text { zontal angle, vertic } \\
\text { al angle, distance } \\
\text { (oblique distance, } \\
\text { horizontal distanc } \\
\text { e) and height diffe } \\
\text { rence measuremen } \\
\text { t }\end{array}$ & $\begin{array}{l}\text { 1) High precisi } \\
\text { on; 2) The effec } \\
\text { tive distance is } \\
\text { long; 3) It is ea } \\
\text { sy to operate; } 4 \text { ) } \\
\text { Low hardware } \\
\text { requirement; 5) } \\
\text { It is not affecte } \\
\text { d by signal stre } \\
\text { ngth }\end{array}$ & $\begin{array}{l}\text { 1) The measure } \\
\text { ment efficiency } \\
\text { is low; } \\
\text { 2) The erection } \\
\text { time is long; } \\
\text { 3) Multiple peo } \\
\text { ple are required } \\
\text { to operate at } \\
\text { the same time }\end{array}$ & $\begin{array}{l}\text { Point mapping, } \\
\text { coordinate poin } \\
\text { t, control point; } \\
\text { The spatial posi } \\
\text { tion of plants, } \\
\text { the corner coor } \\
\text { dinates of build } \\
\text { ing platform, et } \\
\text { c; Elevation sur } \\
\text { vey }\end{array}$ \\
\hline
\end{tabular}




\begin{tabular}{|c|c|c|c|c|}
\hline $\begin{array}{c}\text { laser } \\
\text { laserni } \\
\text { ng }\end{array}$ & $\begin{array}{l}\text { The principle of la } \\
\text { ser ranging is sued } \\
\text { for measurement. } \\
\text { It can be dividedd } \\
\text { into three types: } \mathrm{B} \\
\text { ased on the princip } \\
\text { le of trigonometric } \\
\text { distance measure } \\
\text { ment, phase type a } \\
\text { nd pulse type. Obt } \\
\text { ain point cloud } \\
\text { data efficiently an } \\
\text { d generate 3D soli } \\
\text { d model; The matc } \\
\text { hing of material } \\
\text { and color informat } \\
\text { ion is realized by t } \\
\text { aking pictures } \\
\text { with camera; Wha } \\
\text { t you see is what y } \\
\text { ou get }\end{array}$ & $\begin{array}{l}\text { 1) Accurate, eff } \\
\text { icient, compreh } \\
\text { ensive and reali } \\
\text { stic; 2) The 3D } \\
\text { visualization } \\
\text { model is genera } \\
\text { ted directly, wh } \\
\text { ich is easy to di } \\
\text { splay and sprea } \\
\text { d; 3) Point to p } \\
\text { ont measureme } \\
\text { nt data }\end{array}$ & $\begin{array}{l}\text { 1) It is difficult } \\
\text { to get the top da } \\
\text { ta of large obje } \\
\text { cts; 2) Site setti } \\
\text { ng to avoid blin } \\
\text { d spots; 3) The } \\
\text { threshold of sca } \\
\text { nning range var } \\
\text { ies with differe } \\
\text { nt instruments; } \\
\text { 4) The instrume } \\
\text { nt is expensive } \\
\text { and poor portab } \\
\text { ility; 5) Large a } \\
\text { mount of data, i } \\
\text { nounvenient ma } \\
\text { nagement and ti } \\
\text { me-consuming } \\
\text { post-processin } \\
\text { g; }\end{array}$ & $\begin{array}{l}\text { The scope of ap } \\
\text { plication is very } \\
\text { wide. It has ad } \\
\text { vantages in sur } \\
\text { veying and map } \\
\text { ping complex } \\
\text { and irregular ob } \\
\text { jects, such as o } \\
\text { ckery and large } \\
\text {-scale buildings } \\
\text { with complex } \\
\text { structure; Visu } \\
\text { alization model } \\
\text { is conducive to } \\
\text { the display and } \\
\text { dissemination } \\
\text { of heritage info } \\
\text { rmation }\end{array}$ \\
\hline $\begin{array}{l}\text { Close- } \\
\text { range } \\
\text { photog } \\
\text { ramme } \\
\text { try ob } \\
\text { lique P } \\
\text { hotogr } \\
\text { ammet } \\
\text { rymlos } \\
\text { e to ph } \\
\text { otogra } \\
\text { mmetr } \\
\text { y }\end{array}$ & $\begin{array}{l}\text { It refers to photogr } \\
\text { ammetry by using } \\
\text { stereo pairs of obje } \\
\text { cts with object dist } \\
\text { ance not more than } \\
300 \mathrm{~m} \text {. Acording } \\
\text { to the location of } \\
\text { the camera. it can } \\
\text { be divided into gro } \\
\text { und photogrammet } \\
\text { ry and UUA photo } \\
\text { grammetry. Its wo } \\
\text { rking principle is } \\
\text { to obtain and extr } \\
\text { act the three-dime } \\
\text { nsional informatio } \\
\text { nof of the object } \\
\text { from the image. } \\
\text { blique photograph } \\
\text { y is to collect imag } \\
\text { es from vertical, } \\
\text { front, back, left, ri } \\
\text { ght and left angles } \\
\text { at the same time }\end{array}$ & $\begin{array}{l}\text { 1) A large amo } \\
\text { unt of informati } \\
\text { on of the measu } \\
\text { red object can } \\
\text { be obtained inst } \\
\text { antaneously; 2) } \\
\text { Data processing } \\
\text { is highly autom } \\
\text { ated; 3) I I is eas } \\
\text { y to operate and } \\
\text { the price of the } \\
\text { instrument is } \\
\text { acceptable; } 4 \text { ) } \\
\text { High portabilit } \\
\text { y; 5) Can produ } \\
\text { ce a variety of } f \\
\text { ormats of 3D m } \\
\text { odel data 6) real } \\
\text { istic texture eff } \\
\text { ect }\end{array}$ & $\begin{array}{l}\text { 1) There are ma } \\
\text { ny restrictions } \\
\text { on objective me } \\
\text { asurement cond } \\
\text { itions (such as } \\
\text { weather, light, } t \\
\text { emperature, et } \\
\text { c.); 2) The auto } \\
\text { mation degree } \\
\text { of field operati } \\
\text { on is ot high, } \\
\text { and the data ac } \\
\text { quisition of ima } \\
\text { ge } 3 \text { Do modeling } \\
\text { is difficult; } 3 \text { ) } \\
\text { More photos } \\
\text { are required; } 4 \text { ) } \\
\text { It cant measure } \\
\text { the detail of tar } \\
\text { get tlexibly; } 5 \text { ) } \\
\text { High requireme } \\
\text { nts for data pro } \\
\text { cessing comput } \\
\text { er configuration }\end{array}$ & $\begin{array}{l}\text { It is suitable for } \\
\text { many, wide } \\
\text { and complex ob } \\
\text { jects; Ground } \\
\text { and air multi a } \\
\text { ngle measurem } \\
\text { ent; It is more s } \\
\text { uitable for geo } \\
\text { metry mapping; } \\
\text { Or large-scale } \\
\text { mapping; It has } \\
\text { incomparable a } \\
\text { dvantages for } \\
\text { the digitization } \\
\text { of single cultur } \\
\text { al relics and ex } \\
\text { quisite sculptur } \\
\text { es }\end{array}$ \\
\hline
\end{tabular}

Table 2. Common types and characteristics of digital surveying and mapping technologies in historical gardens.

\section{DIGITAL INFORMATION COLLECTION, ANALYSIS AND CURRENT SITUATION OF MOUNTAIN RESORT}

\subsection{Characteristics of Mountain Resort}

The Mountain resort was built in 1792 after 89 years of Kangxi, Yongzheng and Qianlong dynasties. It is the largest royal garden in Qing Dynasty, covering a total area of 543.5 hectares(Figure 3). Based on the natural mountains, It draws the Wulie River into the park. It uses the low-lying area in the north of the palace area to dig lakes and build mountains and build islands, forming a large-scale natural landscape garden with long dikes, bright lakes and buildings. The natural mountain area covers 418.5 hectares, accounting for $77 \%$ of the total area of the park; The lake area covers 66.1 hectares, accounting for $12 \%$ of the total garden area; The palace area is 12.2 hectares, accounting for only $2.2 \%$ of the total area. The summer resort not only has nearly four fifths of the area of natural mountains, but also hundreds of artificial earth mountains and stone rockeries, which can be regarded as the epitome of the Northern china rockery art.

\subsection{Research status of rockery protection in Mountain Resort}

By 2020, Research on the rockery of Mountain Resort is very weak. Based on the keywords of "rockery in Mountain Resort", "Mountain Resort" and "rockery", the author searched on CNKI, and found only 5 research papers directly related to rockery in Mountain Resort: " Rockeries in the Mountain Resort "(Zhang Yuxin, 1987), "Rockery in Mountain Resort" (Ma Yaping, 1997), "Rockery in Mountain Resort" (Li Fengtong, 1998), "A Brief Introduction to the Rockery in the Mountain Resort"
(Chen Zhenyuan, 1998), "A Comparative Study of Wenyuan Lion Grove and Suzhou Lion Grove" (Li Yang, 2013). Among them, the first four journal papers are the research of the last century. The research content is mainly a general description of rockery in the garden. There is no mapping of rockery, no specific characteristic information about rockery scale, volume, structure, shape, elevation, relationship with buildings, plants and other elements. The above-mentioned research have laid the foundation for rockery research at present, but they do not have the precision required for scientific protection and display of the rockery heritage. The fifth literature is a comparative study on the "Lion Grove in Wenyuan" of the Mountain Resort and the "Lion Grove" in Suzhou. The focus is on the analysis of the relationship between them, the research of rockery is relatively weak, mainly to describe, lack of accurate point cloud data measurement.

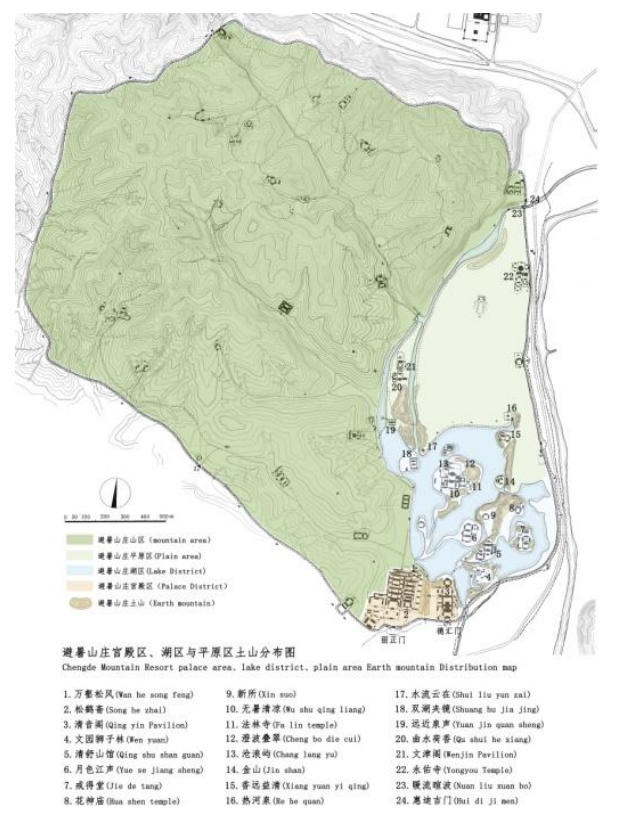

Figure 3. Distribution map of artificial earth mountain in Mountain Resort.(From Wang Yiru)

\subsection{Digital information collection and record of rockery in Mountain Resort}

In order to deeply analyze and study the art of rockery construction in the Mountain Resort and truly protect the rockery heritage, we must first make a comprehensive and detailed inventory of the rockery in the resort, and conduct a comprehensive and detailed digital mapping, photographing and recording of the existing rockery such as Jinshan, Wenyuan Shizilin, etc, and build a database of original information of rockery to provide basic data for long-term monitoring and protection research. The author led the research team to start the investigation and digital surveying of the current situation of rockeries in the Mountain Resort at the beginning of 2019. The research framework is shown in Figure 4. At present, the team has initially completed the preliminary site survey and digital surveying of important rockeries, and has entered the stage of data collation, analysis and in-depth research. The following only takes the digital research of Jinshan rockery as an example to describe the key links of large-scale rockery digital technology. 


\subsubsection{Site features}

Jinshan, located in the northeast of Shanghu, is a near circular island in the east of Ruyi island. Facing the lake in the south, North and West, it has a wide view. It is adjacent to a stream in the East, with a north-south earth mountain barrier. Two stone bridges in the southeast and northeast connect with the east bank. Covering an area of 2900 square meters, it imitates the Jinshan Temple in Zhenjiang, Jiangsu Province to build a group of buildings, which are scattered in the mountain and cleverly integrated with rocks. Jinshan rockery is a large bluestone rockery built in Kangxi Dynasty. The building is a typical practice of covering the mountain. There are also ancient pines and shade .The difficulty of Jinshan rockery surveying and mapping lies in: abundant space, especially the vertical space is complex and changeable; there are many buildings and plants, which hide the rocks; the rockery has many peaks and two caves, and the traffic flow lines are more complicated.

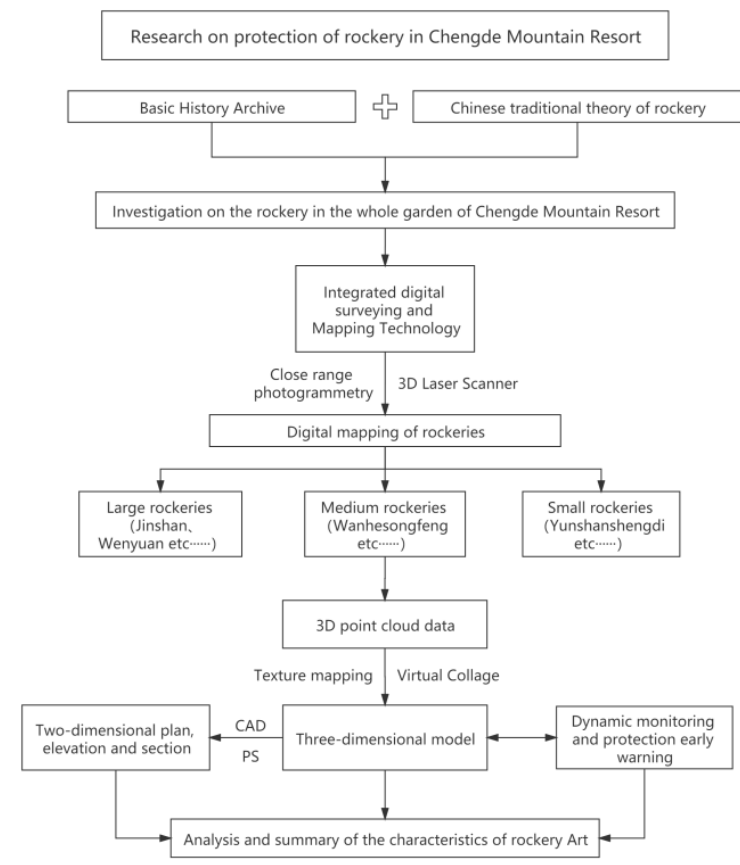

Figure 4. Digital research framework of Mountain Resort rockery.(From Wang Yiru)

\subsubsection{Digital mapping methods and steps}

Because of the irregular shape of the rockery, each stone is different, and it is impossible to establish the module and standard components. In order to display rockery information more comprehensively, it is necessary to start from the overall and detailed levels, and use a variety of surveying and mapping techniques to take into account the overall accuracy and detailed characteristics. Jinshan Surveying and Mapping finally chose ground close-range photogrammetry, UAV tilt Photogrammetry, close to photogrammetry and 3D laser scanning methods to complement each other to ensure the presentation of refined surveying and mapping data. The specific surveying and mapping steps are as follows: UAV preliminary data acquisition (M300rtk UAV equipped with DG4 Pros five-lens camera, P1 camera), collect aerial tilt photography photos and use ContextCapture and photoscan software to process the data, and produce Digital Elevation Model (Digital Elevation Model) Referred to as DEM and 3D model, see Figure5, Figure 7 and Figure 8 for details. Based on the DEM file to plan close-tophotogrammetric routes, the UAV can shoot digital objects at close range from multiple angles at 10-meter intervals and obtain millimeter-level resolution 3D model data. Figure 6 . UAV based on RTK technology (Real-time kinematic, real-time dynamic carrier phase difference technology) can obtain centimeter-level aerial positioning accuracy, combined with high-resolution model photos, can obtain high-precision aerial three-dimensional data, through the station-type 3D laser scanning, cooperating with the ground high-precision positioning camera, it can realize data collection without dead angles in large-scale and local details. Combining with highdensity point cloud modeling can realize high-precision 3D model reconstruction.

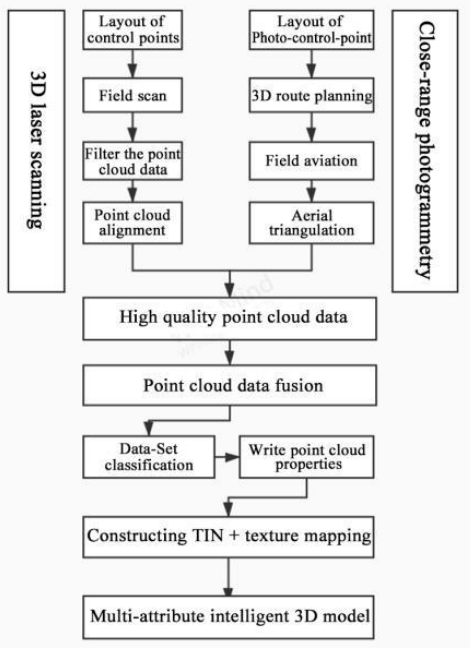

Figure 5. Digital surveying and mapping framework of Jin shan. .(From Xie Lindong)
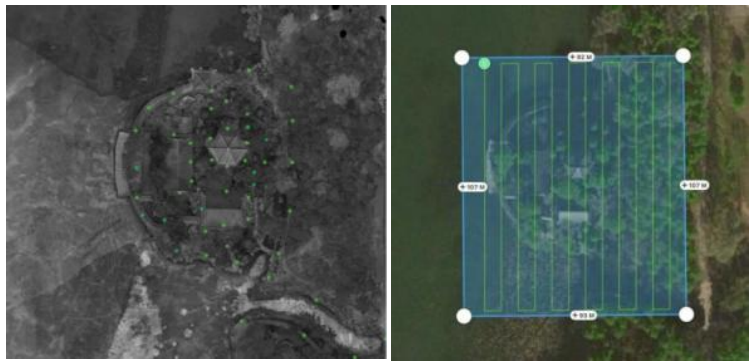

Figure.6-1 Site location of Figure.6-2 Aerial route map Jinshan 3D laser scanner of Jinshan UAV

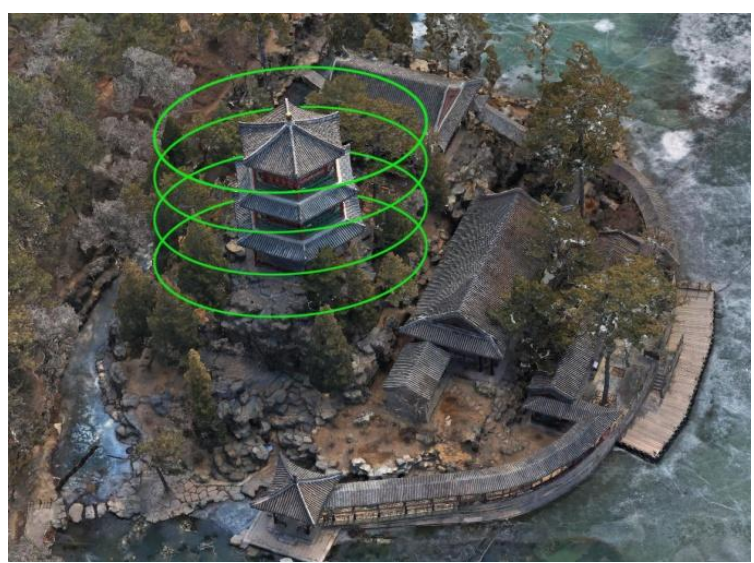

Figure6-3. Aerial route map of close to photogrammetry with UAV (From Xie Lindong) 

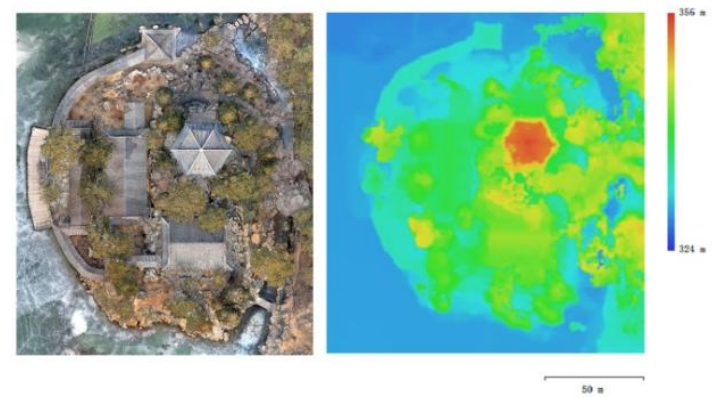

Figure7.Positive image and DEM data of Jinshan tilt photography model (From Xie Lindong)
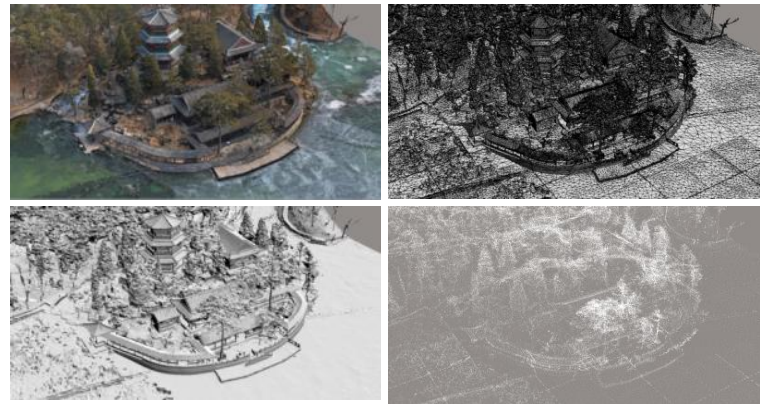

Figure.8 3D model generation by photogrammetry of Jinshan UAV(From Xie Lindong)

\subsubsection{Data fusion processing and visualization}

The current digital data acquisition method is an extension of the spatial surveying and mapping technology based on the new surveying and mapping technology. The core is to obtain the three-dimensional information of the spatial point, and the multi-level point cloud fusion processing finally completes the three-dimensional modeling. Multi-level point cloud data refers to point cloud data of different types, different sites, and different time and space. with different data attributes obtained by laser scanning, image matching, depth image measurement, lidar and other methods. Data fusion is a processing method that relies on the realization of precise spatial precision and consistency.

Obtaining point cloud data is the preliminary result of different digital technology, and processing, fusion and display based on point cloud data is also an important step in digital work. The point cloud classification algorithm PointNet++ based on deep learning is used to realize the point cloud shape classification through 3D shape classification. Its typical application is to separate the tree and outlier point cloud from the overall point cloud to realize the preliminary cleaning of the point cloud and reduce noise. Taking Jinshan as an example, the topography and height difference of the earthy mountains are exposed after clearing the existing trees, which clearly shows the relationship between mountains and waters in the classical garden design. Figure 9.

Point cloud fusion processing is an important way for multisource data to compensate for each other's blind spots. Through the three-dimensional scanning of Jinshan and close to photogrammetry, the ground, indoor and under-eave data are obtained and the lack of roof data is compensated. After processing the close-to-photogrammetric data with Context Capture software, the registered point cloud data is imported into Context Capture, and the software is used for aerial triangulation calculation to obtain the fusion 3D model, which greatly improves the accuracy and details. After the 3D scanning point cloud data software SCENE is matched, the preliminary point cloud of close photogrammetry is added after registration based on the key points to achieve data fusion at the point cloud level.

Point cloud visualization is an important part of data inspection, display, and analysis after fusion. Through the mapping of panoramic images, the point cloud data display effect can be more realistic and more intuitive. Using Bentley Pointools software can realize point cloud video roaming detection, point cloud overlapping editing and loading large scene data through visual performance to make point cloud data more intuitive display.

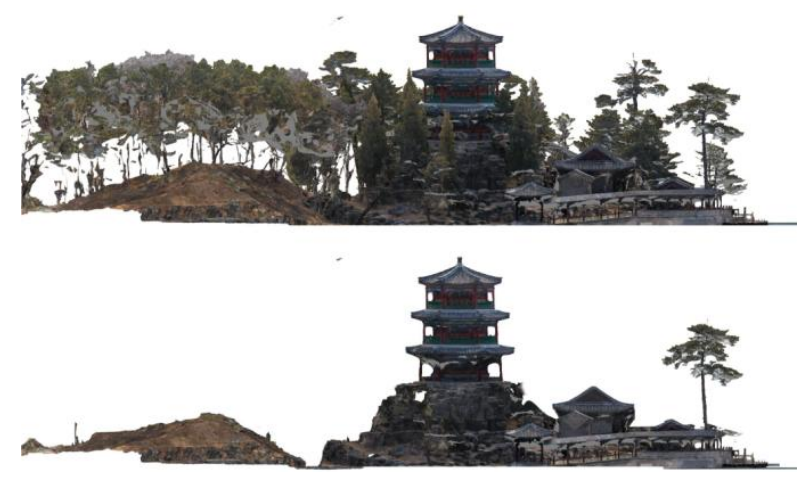

Figure 9. The point cloud classification algorithm based on deep learning can remove the plants around the rockery. (From Xie Lindong)

\subsubsection{Summary}

The progress of modern digital surveying and mapping technology provides a variety of tools for the realization of high-precision digital. However, for different digital objects, such as rockery, it is necessary to select different software and hardware combinations according to the typical characteristics of the objects, and formulate a targeted technical route. There is no technology that can solve all the problems. We need to gradually solve the problems through the combination of different technologies and the technical upgrading of the same principle, such as the application of photogrammetry technology: from orthophoto modeling to oblique photography, and then to close to photogrammetry. In the process of technology improvement and upgrading, we should not indulge in the technology itself, not rely too much on a certain hardware device, achieve balanced development of technology, widely study the technical principles and implementation details, and finally achieve our own use and realize technological innovation.

\begin{tabular}{|c|c|c|}
\hline $\begin{array}{c}\text { Surveying } \\
\text { objects }\end{array}$ & Technical difficulties & Solution \\
\hline Jinshan & $\begin{array}{l}\text { 1. The rocks on the } \\
\text { revetment surrounding the } \\
\text { island are blocked } \\
\text { 2. Dense vegetation shelters } \\
\text { buildings and rockery roofs } \\
\text { 3. Oblique photography is } \\
\text { difficult to obtain front } \\
\text { elevation data } \\
\text { 4. It is difficult to collect } \\
\text { colored paintings and } \\
\text { architectural details under } \\
\text { the eaves of ancient } \\
\text { buildings close distance } \\
\text { 5. The close } \\
\text { between the building and the } \\
\text { rockery is difficult to obtain } \\
\text { all the data by } \\
\text { photogrammetry } \\
6 \text { Multi-source data is } \\
\text { difficult to align during } \\
\text { point cloud fusion }\end{array}$ & $\begin{array}{l}\text { 1. After the lake is frozen, scan the } \\
\text { island from the ice surface } \\
\text { 2. Use aerial data collection when } \\
\text { plants defoliation in winter } \\
\text { 3. Adopt integrated air and ground data } \\
\text { collection to obtain data under the } \\
\text { forest and in the building from the } \\
\text { perspective of the traversing machine. } \\
\text { 4. Hand-held GPS data acquisition } \\
\text { equipment to obtain ground data and } \\
\text { ground looking up data to make up for } \\
\text { the data under the eaves } \\
\text { 5. Obtain DEM data of the field } \\
\text { through multiple flights, import DEM } \\
\text { files into the flight control software, } \\
\text { plan a three-dimensional route around } \\
\text { Jinshan, and obtain data from a } \\
\text { perspective close } \\
\text { photogrammetry to the } \\
\text { 6. The total station or GPS acquires the } \\
\text { control points, and adds the position } \\
\text { data of the control points to the } \\
\text { different data results. }\end{array}$ \\
\hline
\end{tabular}

Table 3. Technical difficulties and solutions of rockery digitization. 


\section{EXISTING PROBLEMS AND PREVENTIVE PROTECTION SUGGESTIONS OF ROCKERY IN THE MOUNTAIN RESORT}

\subsection{Existing problems of rockery}

Through detailed field investigation and digital mapping, it is found that there are the following problems in the rockery of the Mountain Resort, as shown in Figure 10:

1) Due to the natural and man-made destruction of the rockery in the scenic spots of mountain area, the phenomenon of rockery collapse and scattering is serious. For example, due to the structural damage of the rockery near Shan Jin Xuan (the fixed iron components were stolen in the 1960s), the rocks scattered on the ground, and the artistic conception of the rockery space no longer exists;

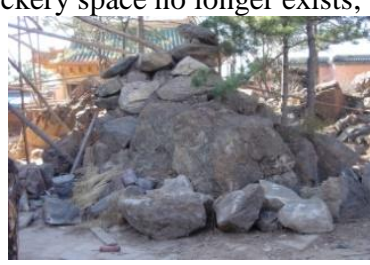

Figure.10-1 scattered in Guanyuan palace

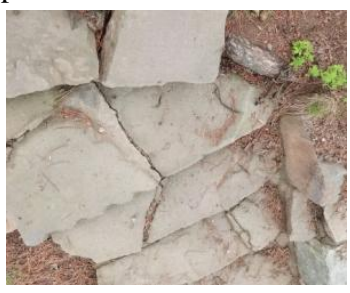

Figure.10-1 Stone stairs fracture in Fangheting

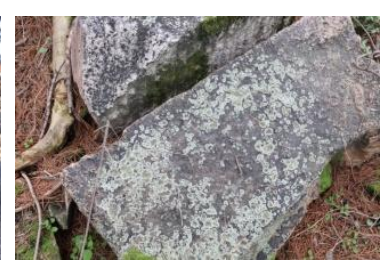

Figure.10-2 Weathering of stone in Shanjinxuan

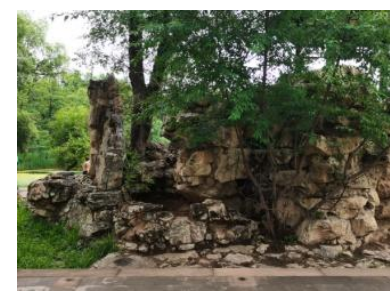

Figure.10-1 Shrub naturally grow from the rockery in Flower temple
2) During the peak tourist season, large and medium-sized rockeries in the lake area are disturbed and damaged by a large number of tourists and climbing activities;

3) The irregular settlement of the rockery has a certain impact on the safety and stability of the upper rockery. For example, the Wenjinge rockery has been monitored for two years by using three-dimensional laser scanning combined with sensor data. According to the comparison of three scanning point clouds, the settlement in the southwest region is obvious in the first year (August 21, 2018 to August 1, 2019), and the maximum settlement is about $99 \mathrm{~mm}$, In the second year (2019.08.01-2020.9.3), the settlement is relatively stable, the settlement rate has decreased, but it is still developing, as shown in Figure $11^{2}$;

4) The growth of plant roots caused some damage to rocks;

5) In some areas, the surface weathering and cracking of rocks are serious, such as the rocks at the back gate of Guangyuan palace; The local revetment or the rockery located in the valley, due to the long-term erosion of water flow, leads to the toppling and collapse of the top stone;

\footnotetext{
${ }^{2}$ From "Wenjin Pavilion rockery in Chengde Summer Resort Safety and stability monitoring report", finished by China Metallurgical Construction Research Institute Co., Ltd and National Center for quality and safety supervision and inspection of industrial buildings
}

6) In the process of restoration, the rockery was not completely repaired according to the principle of authenticity, resulting in secondary damage in the process of restoration.

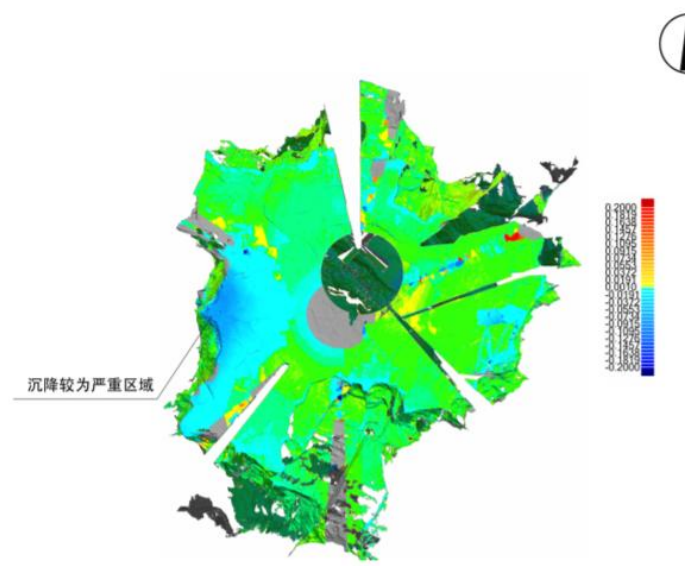

Figure.11 Comparative analysis chart of the first scan point cloud data and the fourth scan point cloud data. Blue area means the settlement in larger than other areas.

\subsection{Suggestions on preventive protection measures}

According to the risks and problems listed in 5.1, the following suggestions are put forward:

1) By means of digital surveying and mapping, a complete information database of rockery is established; At the same time, combined with historical documents and old photos and other information, the paper carries out relevant research to reveal the ideological characteristics and artistic conception characteristics of rockery construction in various scenic spots. Update the data regularly and pay close attention to the dynamic changes of rockery.

2) In order to ensure the safety, we should monitor and control the number of tourists in the rockery areas with large number of tourists, such as the palace area and the lake area;

3) For the rockery with irregular settlement and potential safety hazard, a professional organization should be entrusted to study and formulate the repair plan and establish a long-term monitoring mechanism;

4) Analysis and study of the vegetation in Jinshan, Wenyuan Shizilin, yanyulou and other rockeries, and the vegetation that destroys the stability of rocks should be adjusted or removed; 5) For the rockery stone with weathering phenomenon, it is necessary to analyze the causes of weathering in time, and take measures to avoid or delay the occurrence of weathering phenomenon as far as possible; In order to solve the problems of rockfall caused by water erosion, hydrological analysis should be carried out in relevant areas, and flood or daily precipitation should be reasonably planned and dredged to reduce the damage to rockery and revetment;

6) The rockery repair project should be carefully carried out in strict accordance with the principles of research first, full demonstration, and ensuring the authenticity of historical information.

\section{ACKNOWLEDGEMENTS}

I sincerely thank Chengde Cultural Relics Bureau for its support and all the members of our research team . 


\section{REFERENCES}

Bai Xuefeng., 2015. Study on Digitalization of Chinese Rockery. North China University of Technology, Beijing, China

CHEN Xin, DING Mingjing, YAN Jun., 2020. Research on Pre-conservation of Tuisi Garden from the Perspective of Tourism Development. Landscape Architecture, (12), 24-31.

Elena Lucchi. Review of Preventive Conservation in Museum Buildings[J]. Journal of Cultural Heritage, 2018,29:180-193.

Guo Xiaotong, Yang Chen, Han Feng., 2020. Digital Heritage Landscape: Digital Heritage Landscape: Research on Spatial Character of the Grand Rockery of Yuyuan Garden in Shanghai Based on 3D Point Cloud Technologies. Chinese Landscape Architecture, 36(11), 84-89.

Guo Xiaotong, Yang Chen, Han Feng., 2020. Research on Digital Record and Innovative Conservation of Cultural Landscape Heritage.Chinese Landscape Architecture, 36(11), 84-89.

H. Liang, W. Li, S. Lai, L. Zhu, W. Jiang, Q. Zhang., 2018. The integration of terrestrial laser scanning and terrestrial and unmanned aerial vehicle digital photogrammetry for the documentation of Chinese classical gardens - A case study of Huanxiu Shanzhuang, Suzhou, China. Journal of Cultural Heritage, (33), 222-230.

L. Gu, X. Gu, W. Jan., 2016. The Application of Digital 3D Technology in Garden Surveys: Rockwork as a Case Study. Architectural Journal, pp.35-40.

Li Aiqun, Zhou Kunpeng, Xie Linlin, Wang Chongchen, Yong Xinqun., 2021. Further consideration on preventive protection of Chinese architectural heritage. Chinese cultural heritage, (01), 13-22.

Liang Huilin, Zhang Qingping., 2020. A review of threedimensional digital surveying and information management for garden cultural heritages. Journal of Nanjing Forestry University (Natural Sciences Edition), 44(05), 9-16.

Liang Huilin. Research on 3D digital information of Suzhou Huanxiu villa garden [D]. Nanjing Forestry University, 2018

Mo Jican, Jia Xingxing, Li Lan., 2020. Study on the Preconservation of the Master-of-Nets Garden and its Surrounding Alleys. Landscape Architecture, (12), 17-23.

Mei Wen., 2019. Research on Monitoring and Early Warning System of Garden Heritage. Zhejiang A\&F University, Lin’ an, Zhejiang province, China.

M. Yu, X. Lin., 2017. Study on the Surveying Methods Based upon the 3D Laser Scanning and Close-range Photogrammetry Techniques of the Rockery and Pond in the Classical Chinese Gardens. Landscape Architecture,pp.117-122.

Q. Zhang, H. Liang, W. Li, M. Yang, L. Zhu, A. Huang., 2018. Research of the application of digital survey techniques in private garden. Journal of Nanjing Forestry University (Natural Sciences Edition), 42 (01), 1-6.

Rm, A. , Sa, B., Mgac, D. , Gl, E. , Sa, A. , \& Ga, A., 2021. An historical building information modelling approach for the preventive conservation of historical constructions: application to the historical library of salamanca. Automation in Construction, pp.121.

Remondino F,Rizzia A, Reality based 3D documentation of natural and cultural heritage sites: techniques, problems, and examples [J].Appl. Geomat,2010,2(3):85-100. DOI:10.1007/s12518-010-0025-x)

$\mathrm{Wu}$ Meiping. Theory development and practice overview of preventive protection of architectural heritage from European perspective [J]. Chinese cultural heritage, 2020 (02): 59-78

Wu Meiping. New concept of international heritage protection - Analysis of Preventive Protection of Architectural Heritage. China Cultural Heritage Scientific Research,2011 (2), 90-95.

Wang Qingqing, Dong Qianli, Zhang Qingping., 2020. Research on the Pre-conservation of Spatial Characteristics of Humble Administrator's Garden.Landscape Architecture, (12), 2-9.

Wang Zhe, Zuo Jianming, Song penghao, Luo Yuan., 2020. Study on Pre-protection of Plant Landscape Space in Lingering Garden. Landscape architecture, 344 (12), 23-29.

Wang Shiwei, Hu Jie., 2018. Qianlong Garden in the Digital Perspective [M]. Beijing:China Architecture \& Building Press.

Yang Chen, Han Feng. Digital Heritage Landscape: spatial characteristics of the Yu Garden rockery in Shanghai based on 3D point cloud technology [J]. China Garden, 2018,34 (11): 2024 